\title{
TUBAL ECTOPIC PREGNANCY
}

\author{
BY \\ C. P. DOUGLAS, B.A., M.B., M.R.C.O.G. \\ Senior Lecturer, Department of Obstetrics and Gynaecology, University of the West Indies, Jamaica
}

Tubal pregnancy is the commonest surgical emergency among women in Jamaica. During the years 1954-61, inclusive, 438 ectopic pregnancies (rather more than one a week) were treated in University College Hospital-a ratio of one ectopic for every 28 live births (cf. a figure of $1: 64.2$ reported by Bobrow and Bell in 1962). Of these, $417(95.6 \%)$ were tubal pregnancies. Ten late abdominal pregnancies have been reported previously (Dixon and Stewart, 1960); the rest were early abdominal (9) and ovarian (2). There were 396 patients who had 417 tubal pregnancies (one patient had simultaneous bilateral pregnancies, considered here as one pregnancy). Nineteen patients had a. second tubal pregnancy, and one had two subsequent tubal pregnancies. One patient who had two tubal pregnancies had previously had one removed elsewhere; thus two patients in this series have an overall history of three ectopics (first one tube, then the other, then in the stump); Turner and Ferguson (1956) found only nine such cases in the literature.

\section{Implantation Site}

The site of implantation of the tubal pregnancies and their state at the time of operation are shown in Table I. The distribution by site of implantation is of interest because the proportion of interstitial pregnancies (13\%) is unexpectedly high. Only $11 \%$ were intact pregnancies; the others had ruptured, aborted, or leaked blood into the peritoneal cavity before operation: in six the bleeding was contained entirely between the leaves of the broad ligament.

TABle I.-Site and Type of 417 Tubal Pregnancies

\begin{tabular}{|c|c|c|c|c|c|c|}
\hline \multirow{2}{*}{ Site } & \multicolumn{4}{|c|}{ Type } & \multicolumn{2}{|c|}{ Total } \\
\hline & Ruptured & $\begin{array}{c}\text { Tubal } \\
\text { Abortion }\end{array}$ & Leak & $\begin{array}{c}\text { Not } \\
\text { Ruptured }\end{array}$ & No. & $\%$ \\
\hline \begin{tabular}{lc|} 
Fimbria & $\ldots$ \\
Ampulla & $\ldots$ \\
Isthmus & Interstitial portion \\
Stump &. \\
Not recorded &.
\end{tabular} & $\begin{array}{r}11 \\
83 \\
87 \\
50 \\
9 \\
-\end{array}$ & $\begin{array}{r}11 \\
39 \\
4 \\
- \\
-\end{array}$ & $\begin{array}{r}7 \\
7 \\
7 \\
= \\
-\end{array}$ & $\begin{array}{l}\overline{23} \\
19 \\
4 \\
=\end{array}$ & $\begin{array}{r}29 \\
176 \\
117 \\
54 \\
9 \\
32\end{array}$ & $\begin{array}{r}7 \\
42 \\
28 \\
13 \\
2 \\
8\end{array}$ \\
\hline & $240(57 \%)$ & $54(13 \%)$ & $45(11 \%)$ & $46(11 \%)$ & 417 & 100 \\
\hline
\end{tabular}

Where the site is described as fimbrial, either the rent in the tube extended to the ends of the fimbria or the site of implantation was clearly seen in this part of the tube.

To consider such factors as age and parity, these patients were compared with a similar number of unselected patients who applied to have confinement in hospital. Compared with the control group (median age 24), the patients with ectopic pregnancy were older (median age 28). The comparative age distributions of the two groups are

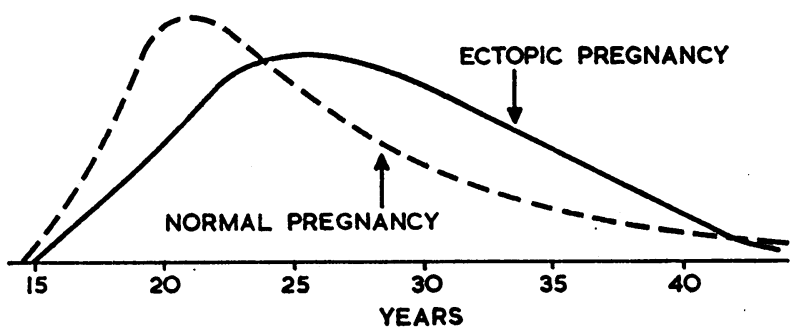

Age distribution of the two groups. shown in the Chart. In the ectopic series $9.6 \%$ of patients gave a history of a previous ectopic pregnancy compared with $0.5 \%$ of the control group. In fertility also there is a marked reduction in the ectopic group ; the total number of conceptions before the ones studied here was 710 in the ectopic group and 829 in the normal group (significant at the $1 \%$ level).

Side.-In $54.7 \%$ the pregnancy was in the right tube and in $40.8 \%$ in the left (not recorded $4.5 \%$ ). This is statistically significant $(P=0.004)$; a similar finding has been noted in another large series (Sandmire and Randall, 1959).

\section{Evidence of Previous Infection}

Very few patients can or will give an accurate history of previous pelvic infection, and only findings at operation can provide the evidence. There was gross or microscopical proof of previous infection in $42 \%$ of our patients (Table II). The Fallopian tubes, however, were routinely sectioned only at the site of implantation of the pregnancy. Recently in 50 consecutive cases serial sections were made in this hospital from the whole tube ; $48 \%$ of these showed chronic salpingitis, $10 \%$ had abnormal fibrosis or agglutination of mucosal folds, and in the remaining $42 \%$ there was no evidence of infection (Stirling and Castor, 1962). It therefore seems that tubal pregnancy is associated with evidence of previous infection in about half the cases.

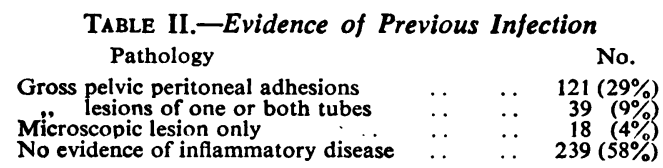

Although other pelvic lesions may occur in association with tubal pregnancy their influence on its occurrence is uncertain. Fibroids (19), ovarian tumours (10), previous tubal ligation (2), and previous laparotomy (15) were the associated factors in this series.

\section{Symptoms and Mode of Onset}

It is convenient to group the patients, according to the time of onset of symptoms, into those whose symptoms began suddenly, less than 24 hours before admission (174, $41 \%)$; those with a longer and more chronic history (134, $32 \%)$; and those with an acute-on-chronic sequence (109,

\begin{tabular}{|c|c|c|c|c|c|}
\hline \multirow{2}{*}{ Symptoms } & \multicolumn{2}{|c|}{ Total } & \multirow{2}{*}{ Acute } & \multirow{2}{*}{$\begin{array}{l}\text { Acute- } \\
\text { on- } \\
\text { Chronic }\end{array}$} & \multirow{2}{*}{ Chronic } \\
\hline & No. & $\%$ & & & \\
\hline $\begin{array}{l}\text { A. Principal: } \\
\text { Pain alone } \\
\text { Bleeding alone } \ldots \\
\text { Pain and bleeding }\end{array}$ & $\begin{array}{r}249 \\
16 \\
122\end{array}$ & $\begin{array}{r}60 \\
4 \\
29\end{array}$ & $\begin{array}{r}122 \\
2 \\
26\end{array}$ & $\begin{array}{r}102 \\
4 \\
3\end{array}$ & $\begin{array}{l}25 \\
10 \\
93\end{array}$ \\
\hline $\begin{array}{l}\text { B. Additional } \\
\text { Fainting } \ldots \\
\text { Vomiting } \\
\text { Shoulder-tip pain } \\
\text { Urinary symptoms }\end{array}$ & $\begin{array}{r}67 \\
55 \\
41 \\
7\end{array}$ & $\begin{array}{r}16 \\
13 \\
10 \\
2\end{array}$ & $\begin{array}{r}48 \\
43 \\
23 \\
3\end{array}$ & $\begin{array}{r}11 \\
5 \\
3 \\
1\end{array}$ & $\begin{array}{r}8 \\
7 \\
15 \\
3\end{array}$ \\
\hline
\end{tabular}

* Anuria for 18 hours (1), acute retention (3), and dysuria with frequency (3).

$27 \%$ ). Table III shows that pain is a much more common symptom than is vaginal bleeding in the acute and acuteon-chronic groups, whereas bleeding occurs nearly as often as pain in the more chronic type of case. Bleeding preceded pain in only $12 \%$ of patients. The additional 
presenting symptoms, such as fainting and vomiting, are much more common when the onset is acute.

Shoulder-tip pain was a complaint in 41 patients, but it is interesting that in nine of them no blood was found in the peritoneal cavity at operation. This is surprising, and suggests that leading questions may have been asked or that blood is not the only cause of this pain.

\section{Menstrual History}

One patient in five gave a menstrual history which was so vague and uncertain as to be valueless. Among those with a clear menstrual history the number of missed periods is shown in Table IV. Two patients had not started to menstruate after a previous pregnancy. Many patients therefore miss at least two periods before the tube ruptures. Conversely, in many the tube ruptures before a period is missed.

$$
\begin{gathered}
\text { TABLE IV.-Amenorrhoea } \\
\text { "Missed Periods" }
\end{gathered}
$$

Other early symptoms of pregnancy, such as morning nausea and tingling of the breasts, are uncommon with tubal pregnancy ; and few patients, even experienced multiparae, admitted that they "felt pregnant." Only nine patients in the whole series had noted the classical dark "prune-juice" type of vaginal discharge, or were found to have it when examined.

\section{Clinical Examination}

The most consistently helpful finding on abdominal examination is rebound tenderness, which may be general or localized. Detection of intraperitoneal bleeding by seeking evidence of free fluid is not reliable; the signs are difficult to elicit if there is less than $100 \mathrm{ml}$. or more than $1,500 \mathrm{ml}$. of blood in the abdomen. When much blood is present it produces a doughy, tumid feeling which is characteristic.

On vaginal examination there is often very severe pain when the cervix is moved or even gently touched. If the vagina is not unusually hot and this cervical excitation pain is marked, the diagnosis is probably ectopic pregnancy rather than acute inflammatory disease, in which the greatest tenderness is usually in the fornices. The tenderness is often so great that the uterus and adnexa cannot be felt. Enlargement of the uterus or adnexal swellings are not particularly helpful in confirming or excluding a diagnosis of ectopic pregnancy, and there is little point in hurting the patient and perhaps deepening her shock by persisting in a very painful examination. The tubal pregnancy ruptured during pelvic examination in 10 of our patients, which is reason enough for advising that such examination should not be done in the patient's home.

\begin{tabular}{|c|c|c|c|c|}
\hline Sign & & $\begin{array}{c}\text { Noted as } \\
\text { Present }\end{array}$ & $\begin{array}{c}\text { Noted as } \\
\text { Absent }\end{array}$ & $\begin{array}{c}\text { Not } \\
\text { Noted }\end{array}$ \\
\hline $\begin{array}{l}\text { Rebound tenderness } \\
\text { "Free fluid" } \\
\text { " Cervical excitation pain" } \\
\text { Abnormal pelvic mass }\end{array}$ & $\begin{array}{l}\cdots \\
\cdots \\
\cdots\end{array}$ & $\begin{array}{l}307 \\
197 \\
279 \\
101\end{array}$ & $\begin{array}{r}82 \\
157 \\
27 \\
32\end{array}$ & $\begin{array}{r}28 \\
63 \\
111 \\
284\end{array}$ \\
\hline
\end{tabular}

TABLE V.-Common Clinical Findings

The incidence of these common clinical findings is shown in Table $\mathrm{V}$.

A degree of shock was present in most patients, but it was not necessarily related to the amount of intraperitoneal bleeding. Some patients who had lost only a little blood were severely shocked and some who had lost a great deal were apparently in good general condition. Some individuals lose a lot of blood but may not develop profound shock for several hours. These cases may be misleading because the patients look so well and may even have walked several miles to hospital ; signs of free fluid, a slow pulse (60 or less per minute), and a normal or slightly raised blood-pressure demand immediate attention.

Haemoglobin and packed-cell-volume values are informative only if they are really low; the leucocyte count is quite unreliable, although a high figure in the chronic case may be helpful.

\section{Errors in Diagnosis}

The frequency of ectopic pregnancy in Jamaica engenders a high index of suspicion in the hospital staff, and women with acute abdominal symptoms are referred to the gynaecologists rather than to the general surgeons. In the present series the pre-operative diagnosis of tubal pregnancy was considered to be "certain" in $72 \%$, " uncertain" in $14 \%$, and the other $14 \%$ were at first incorrectly diagnosed and were treated for some other condition.

This group of cases that were not at first correctly diagnosed is compared in Table VI with the 35 patients (not, of course, included in this series but seen in the same period) who were at first considered to have tubal pregnancies-19 " certain," 16 " uncertain."

\begin{tabular}{|c|c|c|c|c|}
\hline \multicolumn{2}{|c|}{$\begin{array}{c}\text { Ectopic Pregnancy Diagnosed as Other } \\
\text { Conditions }\end{array}$} & \multicolumn{3}{|c|}{$\begin{array}{l}\text { Other Conditions Diagnosed as } \\
\text { Ectopic Pregnancy }\end{array}$} \\
\hline $\begin{array}{l}\text { Pelvic inflammatory disease } \\
\text { Incomplete abortion ... } \\
\text { Threatened ,. .. } \\
\text { Hyperemesis gravidarum } \\
\text { Other .. . . . . }\end{array}$ & $\begin{array}{r}34 \\
8 \\
5 \\
2 \\
8\end{array}$ & $\begin{array}{l}\text { Acute salpingitis } \\
\text { Ovarian lesions } \\
\text { Intrauterine pregnancy } \\
\text { Bicornuate uterus and } \\
\text { dysmenorrhoea }\end{array}$ & $\begin{array}{r}\ldots \\
\ldots \\
\text { severe } \\
\ldots\end{array}$ & $\begin{array}{r}17 \\
8 \\
9 \\
1\end{array}$ \\
\hline Total & 57 & Total & & 35 \\
\hline
\end{tabular}

Table VI.-Mistakes in Diagnosis

Pelvic infection and intrauterine pregnancy emerge as the two main causes of confusion. We do not think that it is always possible to differentiate either of these clearly from ectopic pregnancy. Even "proof puncture" of the pouch of Douglas may be misleading - it yielded blood in two out of three cases of acute salpingitis-and also it may be both misleading and dangerous if the pouch of Douglas has been obliterated by adhesions. Passage of a decidual cast in association with a tubal pregnancy cannot be distinguished from an incomplete abortion until the tissue has been examined under the microscope, and sometimes not even then. Finally, there may be coincident intrauterine and tubal pregnancies. There were four such in this series $(0.9 \%)$ : two continued to term (one was treated with progesterone after operation), one had aborted before admission, and the other aborted after laparotomy. On the whole "if in doubt, open" is a better policy than "wait and see." Half the patients who had a laparotomy done because of a mistaken diagnosis of ectopic pregnancy had some other condition which needed surgical treatment. Nine patients were found to have an intrauterine pregnancy ; four of these continued to term and five abortedimpending abortion was apparently the cause of the acute symptoms.

\section{Treatment}

When a diagnosis of tubal pregnancy is made or even suspected, laparotomy is indicated. If the patient is in shock nothing is gained by prolonged "resuscitation"; the patient will recover more quickly if the bleeding tube is clamped off and then blood is replaced. Delay is 
dangerous, and immediate laparotomy often life-saving. The operations which were done in this series are listed in Table VII.

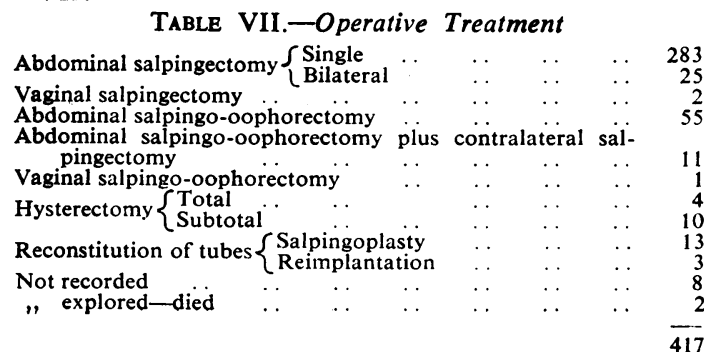

The policy in this unit has been to find and to control the source of bleeding and then to carry out the simplest adequate operative procedure. Usually this is total salpingectomy, which is preferred to partial salpingectomy because of the risk of a subsequent ectopic pregnancy in the tubal stump. Where the ovary is adherent to the damaged tube or has been injured by haemorrhage into and around the broad ligament, it is removed also. If the opposite tube is diseased it is excised if this can be done without undue difficulty. If the uterus has been greatly damaged by rupture of the interstitial part of the tube, hysterectomy may be necessary; it is often safer than resection of the damaged cornu. The appendix is removed only if it is adherent to the region of the affected tube. Operations designed to preserve the function of a damaged tube are very rarely successful and they are often followed by a second tubal pregnancy. Consequently this type of operation has been done only in a few patients who particularly desired further pregnancy and whose general condition was good at the time of operation.

\section{Blood Transfusion}

Blood transfusion was given to 272 patients $(65 \%)$ in this series; two others were given a plasma expander only. Autotransfusion was used in $43 \%$ of all cases. The largest amount of blood returned to the patient in this way was 4 pints $(2,280 \mathrm{ml}$.). There have been no complications after autotransfusion. The blood is not used unless it seems to be fresh, is normal in colour, free of odour, and is believed from the history to have been in the peritoneal cavity for not more than 12 to 24 hours. Applying these criteria, autotransfusion was given to three-quarters of the patients who had a reasonable quantity of blood in the peritoneal cavity. TABLE VIII.-Source of Transfusion Fluid Donor blood only
Autotransfusion on $93(22 \%)$
$80(19 \%)$
$99(24 \%)$ Plasma expande No transfusion Both of above $2(0.5 \%)$

Blood for autotransfusion is ladled with a small gallipot into a bowl which contains $5 \mathrm{ml}$. of $3.8 \%$ sodium citratethat is, half the usual amount for 2 pints $(1,140 \mathrm{ml}$.). The bowl is covered with a double layer of gauze to filter out clots. When enough blood has been collected it is drawn into a standard vacuum transfusion bottle and used immediately. Where these means are not available the blood may be collected by aspirating it direct into a transfusion bottle from a Denis Browne strainer dipped into the pool of blood in the abdomen (Markowski, 1959). Blood from the abdominal cavity must never be used for another patient or be kept more than a few.hours before use.

\section{Post-operative Complications}

The patients are generally in good health before the ectopic pregnancy ruptures. This, together with adequate blood transfusion, may account for the fact that postoperative complications are few. Mild pyrexia, perhaps due to reabsorption of blood from the peritoneal cavity, occurred in 56 patients (13\%); superficial wound dehiscence required resuture in seven; deep-vein thrombosis occurred in six and non-fatal pulmonary embolism in two; one patient developed a pelvic abscess and one a subphrenic abscess. The patients were usually fit for discharge on the sixth or seventh day.

\section{Mortality}

There were five deaths in the series, a mortality rate of $1.2 \%$. Two of these patients were moribund on admission and died before they could be taken to the theatre. Three died after operation-two from myocardial failure, pulmonary oedema, and anuria, and one from the effects of cerebral anoxia following prolonged severe shock; the latter had been treated expectantly elsewhere with a diagnosis of chronic appendicitis, and the pregnancy was found to be in the left ampulla. Table IX shows that in four of these patients the symptoms were of sudden onset and short duration; the pregnancy was either in the interstitial portion or in the isthmus of the tube. Sudden massive haemorrhage seems to occur most often in these areas, and such implantations are the most likely to be fatal.

\begin{tabular}{|c|c|c|c|c|c|}
\hline $\begin{array}{l}\text { Case } \\
\text { No. }\end{array}$ & Age & Parity & $\begin{array}{l}\text { Symptoms } \\
\text { and Mode } \\
\text { of Onset }\end{array}$ & $\begin{array}{c}\text { Duration } \\
\text { of } \\
\text { Symptoms }\end{array}$ & $\begin{array}{c}\text { Site } \\
\text { of } \\
\text { Pregnancy }\end{array}$ \\
\hline 1 & 38 & $0+2$ & Pain, chronic, and & 36 hours & Ampulla \\
\hline $\begin{array}{l}2 \\
3 \\
4 \\
5\end{array}$ & $\begin{array}{l}20 \\
23 \\
23 \\
23\end{array}$ & $\begin{array}{c}1+0 \\
1+0 \\
?+0 \\
1+0\end{array}$ & $\begin{array}{c}\text { Pain, acute } \\
\text { ", " } \\
",\end{array}$ & $\begin{aligned} 13 & , \\
5 & , \\
5 & \Rightarrow \\
5 & \text { ", }\end{aligned}$ & $\begin{array}{l}\text { Isthmus } \\
\text { Interstitial }\end{array}$ \\
\hline
\end{tabular}

\section{Subsequent Pregnancies}

It is unlikely that all our patients returned to University College Hospital if they became pregnant again, but local custom is such that very probably most of them did. Of the 396 patients in this series 178 were seen again for one reason or another more than one year after operation. Sixty-nine of these patients had again conceived during an average period of four years, nine of them twice. In.'all they had 49 viable deliveries, 10 abortions, and 19 tubal pregnancies. The incidence of repeat ectopic pregnancy is therefore probably of the order of $10 \%$. There was no significant difference in the occurrence of subsequent pregnancies between patients who had had many previous pregnancies and those who had had none.

\section{Discussion}

Both pelvic inflammatory disease and ectopic pregnancy are much more common in Jamaica than in the United Kingdom, but in both countries the proportion of patients with tubal pregnancy who also show evidence of previous pelvic inflammation is about the same. Other causative factors, whatever they may be, must also be more common in the West Indies. We can produce no evidence for or against the hypothesis that antibiotic therapy of pelvic infections has produced a greater legacy of tubes which are patent but distorted or narrowed, so causing an increase in the number of tubal pregnancies (Krohn et al., 1952). Although no histological change is evident in the tubes, it may be that changes in cell function as a result of "cure" by antibiotics may affect the physiological or secretory mechanisms in the tube. This could result in decreased peristalsis, ciliary propulsion, or secretion which concerns 
the capacitation of the sperm (Lowi, 1960), or might delay onward passage of the fertilized ovum. The relative infertility of the women in Jamaica who have a tubal pregnancy is consistent with the finding in Britain that the incidence of ectopic pregnancy in women who had been investigated for infertility was eight times the incidence among other women in the same community (Wyper, 1962).

Transperitoneal migration of the ovum from the ovary of origin to the contralateral tube has been postulated as a cause of ectopic pregnancy, and in some series it has been thought to account for $50 \%$ of cases (Berlind, 1960). A contralateral corpus luteum was noted in only 23 patients in our series. There are, of course, many possible causes which cannot be evaluated in a study such as thispsychogenic factors which may cause tubal spasm, for example. Only the gross aetiological changes and their. influence have been considered.

Abdominal pain is the most severe and constant symptom in tubal pregnancy, very often present before the tube had ruptured. It is probably the result of stretching of the tube wall. When the tube ruptures, or occasionally when a tubal abortion takes place, acute pain occurs. It is commonly believed that this pain is due to peritoneal irritation by the blood, but this may not be so. Intraperitoneal blood infusion is almost painless (Cole and Montgomery, 1929 ; McDougall, 1958 ; Mellish and Wolman, 1958); and Mengert et al. (1951) showed that intraperitoneal infusion of up to $300 \mathrm{ml}$. of blood produced only a feeling of fullness. Larger quantities (300 to 500 ml.) caused pain of short duration. Whatever its cause, the abdominal pain of a ruptured tubal pregnancy is often severe, and usually continues unabated until operation. It must be remembered, however, that a few patients have no, pain, tenderness, or rigidity, although the abdominal cavity is full of blood.

In diagnosis the most constant and so most useful signs are abdominal tenderness, particularly when accentuated by rebound, and extreme pain produced by the slightest movement of the cervix. These are both, presumably, evidence of peritoneal irritation, probably in the region of the lesion itself, since they are found even when the pouch of Douglas, suggested as the site of pain by Irwin (1960), is obliterated by adhesions. These two symptoms may be present when there has not been enough bleeding to produce signs of free fluid. If a large quantity of blood has clotted among loops of gut it is difficult to find proof of free fluid. Shoulder-tip pain, usually said to be a frequent symptom, is in fact uncommon.

The degree of shock bears no constant relation to the amount of intraperitoneal bleeding. When shock is considerable but there has been little haemorrhage one must postulate some other contributory cause, possibly damage and tearing of the tissues of the tube and mesosalpinx. This response to only a small loss of blood is perhaps more often seen in the tropics, where the response of the adrenals to shock may be diminished (Stirling and Keating, 1958).

Resuscitation, including copious blood transfusion, does not usually much improve the condition of the patient with an ectopic pregnancy who is already in shock. But the blood-pressure usually begins to rise and the pulse becomes stronger-quite dramatically-immediately clamps are placed on the damaged tube. Why this should happen is obscure; frequently there is no active bleeding from the tube when the abdomen is opened. Investigation of this phenomenon might give some information about factors which are involved in the causation and relief of shock. Once the tube hás been clamped, rapid blood transfusion should be given; and at this time, also, blood for autotransfusion is available.

Autotransfusion has been shown to be safe and effective, and there seems to be no good reason why a patient's own blood should be thrown away even where ample supplies of donor blood are available. The procedure has often been advocated in England (Moir, 1960; Stabler, 1934, $1960)$ but seldom practised. In most tropical countries autotransfusion may save some lives and speed the convalescence of many patients.

Our experience with conservative tubal surgery or tubal reconstruction has been small, but we believe there is little place for anything less than complete removal of the damaged tube in a community where associated pelvic pathology and repeated tubal pregnancies are common. It has been clearly shown elsewhere that conservative surgery is followed by considerable increase in subsequent repeat ectopic pregnancies (Ploman and Wicksell, 1960).

\section{Summary}

The records of 417 tubal pregnancies which occurred in 396 patients over a period of eight years at University College Hospital, Jamaica, are reviewed. The incidence was one ectopic pregnancy to 28 live births.

Although the data do not throw much light on the problems of aetiology, they indicate that certain symptoms hitherto considered to be typical, such as amenorrhoea shoulder-tip pain, and "prune-juice" bleeding, may be quite uncommon. Other features, such as abdominal rebound tenderness and severe pain on movement of the cervix, are very useful in diagnosis. The problems of diagnosis are considered in the light of errors made during the years reported in this series.

In treatment, a policy of immediate operation, supplemented by transfusion of blood, either from a donor or by autotransfusion from blood in the abdominal cavity, is justified, we believe, by the low mortality rate of $1.2 \%$.

The incidence of a second or third ectopic pregnancy in these patients is of the order of $10 \%$.

I wish to thank Professor D. B. Stewart for his encouragement and valuable criticism in the preparation of this paper; Dr. H. G. Dixon for his help in searching the early records; and all members of the staff of the department, past and present, for making this study possible.

\section{REFERENCES}

Berlind, M. (1960). Obstet. and Gynec., 16, 51.

Bobrow, M. L., and Bell, H. G. (1962). Ibid., 20, 500.

Cole, W. C. C., and Montgomery, J. C. (1929). Amer. J. Dis. Child., 37, 497.

Dixon, H. G., and Stewart, D. B. (1960). Brit. med. J., 2, 1103.

Irwin, H. W. (1960). Obstet. and Gynec., 16, 327.

Krohn, L., Priver, M. S., and Gotlib, M. H. (1952). J. Amer. med. Ass., 150, 1291 .

Lowi, R. N. P. (1960). Obstet. and Gynec., 16, 322.

McDougall, L. G. (1958). Brit. med. J., 1, 139.

Markowski, B. (1959). W. Indian med. J., 8, 229.

Mellish, P., and Wolman, I. J. (1958). Amer. J. med. Sci., 235, 717. Mengert, W. F., Cobb, S. W., and Brown, W. W., jun. (1951). J. Amer. med. Ass., 147, 34.

Moir, J. C. (1960). Lancet, 1, 491

Ploman, L., and Wicksell, F. (1960). Acta obstet. gynec. scand., 39, 143.

Sandmire, H. F., and Randall, J. H. (1959). Obstet. and Gynec., 14, 227.

Stabler, F. (1934). J. Obstet. Gynaec. Brit. Cwlth, 41, 768.

- (1960). Lancet, 1, 599.

Stirling, G. A., and Castor, U. S. (1962). W. Indian med. J., 11, 45. - and Keating, V. J. (1958). Brit. med. J., 2, 1016.

Turner, H. B., and Ferguson, T. M. (1956). Amer. J. Obstet. Gynec., 72, 433.

Wyper, J. F. B. (1962). Brit. med. J., 1, 273. 